\title{
The Human Rosette-Forming Cell as a Marker of a Population of Thymus-Derived Cells
}

\author{
Joseph Wybran, Martin C. Carr, and H. Hugh Fudenberg \\ From the Section of Hematology and Immunology, Department of Medicine, \\ and the Department of Obstetrics and Gynecology, School of Medicine, \\ University of California, San Francisco, California 94122
}

A B S T R A C T Sheep red blood cells can surround, in vitro, some human peripheral blood lymphocytes in a formation called a rosette. The number of rosetteforming cells (RFC) in 50 normal persons had a wide range $(4-40 \%)$.

The organs of 13 human fetuses (11-19 wk conceptional age) were examined for the presence of RFC. The thymus possessed the highest percentage of RFC, the maximum being $65 \%$ of total thymocytes in two 1516 wk fetal specimens. Blood RFC were always present and their number slightly increased in the oldest fetuses. The bone-marrow showed $0-8 \%$ in the six fetuses studied. RFC were found in the spleen around the 13 th wk and in the liver around the 17th wk of gestation. These observations lead to the hypothesis that human blood RFC may be chiefly thymic derived. Studies of patients with immunological disorders support this hypothesis: one patient with Nezelof syndrome had no blood RFC and four patients with Wiskott-Aldrich syndrome had a low number of blood RFC (1 and $1.5 \%)$. Patients with acquired hypogammaglobulinemia showed a normal percentage of RFC. With the fetal thymocytes, the percentage of inhibition with anti- $\mu$ serum increased with the fetal age to become complete in the oldest fetuses studied. Incubation of the oldest fetal thymocytes or the blood lymphocytes with anti- $\gamma$ serum or anti- $\mu$ serum completely inhibited the rosette formation. These results suggest that $\mu$-chain determinants are present on human fetal thymocytes and blood RFC. The significance of the presence of $\boldsymbol{\gamma}$-chain determinants on these cells is unclear.

Presented in part at the 84th annual meeting of the Association of American Physicians, 4 May 1971, Atlantic City, N. J. (Wybran, J., H. H. Fudenberg, and M. H. Sleisenger. 1971. Rosette formation, a test for cellular immunity. Clin. Res. 19: 568).

Received for publication 29 November 1971 and in revised form 29 March 1972.

\section{INTRODUCTION}

The adherence of sheep red blood cells $(\mathrm{SRBC})^{1}$ to a lymphocyte results in a formation termed a rosette (1-4). Rosettes are formed by a small percentage of lymphocytes from peripheral blood of normal nonimmunized people. The significance of rosette formation in man is not well understood. Its role as an immunological tool is still controversial, although inhibition of the normal rosette formation by anti-lymphocyte serum (ALS) has been shown to be a very sensitive index of the immunosuppressive activity of various ALS preparations (1). In order to obtain information on this phenomenon and to investigate its significance, the present study was conducted in human fetuses.

\section{METHODS}

\section{Materials}

Fetal tissues. Fetuses were obtained at time of abdominal hysterotomies for therapeutic abortions and processed immediately. Fetal age was derived from the measurement in millimeters of crown-rump length, in accordance with data of the Carnegie embryological collection (5).

Thymus, spleen, and liver were obtained by sharp dissection, minced, and homogenized. ${ }^{2}$ The homogenates were passed through fiberglass wool contained in a syringe, resulting in a single cell suspension for each organ. Bone marrow was obtained by flushing the epiphyseal ends of long bones with a syringe and a small-gauge needle. All cells were washed three times in phosphate-buffered saline ( $\mathrm{PBS}, \mathrm{pH} 7.3$ ).

Blood. Blood was obtained from 50 normal human subjects (18 months to $81 \mathrm{yr}$ old) and from 8 patients with immunological disorders. This group was composed of three patients with acquired hypogammaglobulinemia, four with

\footnotetext{
${ }^{1}$ Abbreviations used in this paper: ALS, anti-lymphocyte serum; FT-RFC, fetal thymic rosette-forming cells; PBS, phosphate-buffered saline; PHA, phytohemagglutinin; PPD, purified protein derivative; RFC, rosette-forming cells; SRBC, sheep red blood cells; T.F., transfer factor.

${ }^{2}$ Potter-Elvehjem tissue grinder, Kontes Glass Co., Vineland, N. J.
} 
TABLE I

Rosette-Forming Cells in the Organs of Human Fetuses

\begin{tabular}{rcccccc}
\hline & & \multicolumn{5}{c}{ Organ* } \\
\cline { 5 - 7 } Fetus & $\begin{array}{c}\text { Gesta- } \\
\text { tional } \\
\text { age }\end{array}$ & Thymus & Blood & Spleen & Liver & $\begin{array}{c}\text { Bone } \\
\text { marrow }\end{array}$ \\
\hline & $w k$ & $\%$ & $\%$ & $\%$ & $\%$ & $\%$ \\
1 & 11 & 15 & 1.0 & N.P.t & 0 & 0.5 \\
2 & 12 & 28 & N.D. & 0 & 0 & N.D. \\
3 & 12 & 48 & 0.5 & 0 & 0 & N.D. \\
4 & 13 & 35 & 0.5 & 0 & 0 & N.D. \\
5 & $13-14$ & 15 & 0.5 & 0.5 & 0 & 0 \\
6 & $13-14$ & 50 & 0.5 & 0.5 & 0 & N.D. \\
7 & 15 & 65 & N.D. & N.D. & N.D. & 3.0 \\
8 & 15 & 47 & 0.5 & 0.5 & 0 & N.D. \\
9 & $15-16$ & 65 & N.D. & N.D. & N.D. & 1.0 \\
10 & 17 & 35 & 2.0 & 4.0 & 2 & 0.5 \\
11 & 18 & 24 & 11.0 & 11.0 & 1 & 8.0 \\
12 & 19 & 30 & N.D. & N.D. & N.D. & N.D. \\
13 & 19 & 30 & 2.5 & 2.5 & 0 & N.D. \\
\hline
\end{tabular}

* Results are reported as the mean of duplicate determinations in all organs except the bone marrow, where only one determination was done. $\ddagger$ N.P., not present.

$\$$ N.D., not done.

Wiskott-Aldrich syndrome, and one with Nezelof syndrome. The blood was collected in heparinized syringes. ${ }^{3}$ Fetal blood was obtained by draining the cut end of the umbilical cord into heparinized tubes. Lymphocytes were isolated in a gradient of $9 \%$ Ficoll-34\% Hypaque according to the method of Harris and Ukaejiofo (6). The lymphocytes were washed three times in $10 \mathrm{ml}$ of $\mathrm{PBS}(\mathrm{pH} 7.3)$ and their concentration was adjusted to $5 \times 10^{6} / \mathrm{ml}$. Except in the fetal blood, the ABO group and the titer of hemagglutinating antibodies against SRBC were determined.

Antisera. Antisera were prepared in goats and rabbits. Pure heavy-chain or light-chain proteins were isolated from myeloma proteins or Bence Jones proteins by precipitation with $\mathrm{Na}_{2} \mathrm{SO}_{4}$ and fractionation in a DEAE column.

The antisera were rendered monospecific by successive absorptions with aggregates of the appropriate types of heavyand light-chains cross-linked with glutaraldehyde (7). The antisera were heat inactivated at $56^{\circ} \mathrm{C}$ for $30 \mathrm{~min}$ and absorbed with SRBC and human red blood cells, twice at $37^{\circ} \mathrm{C}$ and twice at $4^{\circ} \mathrm{C}$. No agglutination of red cells was detected after these procedures. Specificity was determined by gel diffusion and by the more sensitive $\mathrm{CrCl}_{3}$ hemagglutination inhibition method (8). The following titers, assessed by the latter method, were obtained: goat anti- $\alpha, 1: 600,000$; rabbit anti- $\gamma, 1: 600,000$; goat anti- $\mu, 1: 600,000$; rabbit anti- $\kappa, 1: 640$; and rabbit anti- $\lambda, 1: 2560$.

Horse antiserum to human $\epsilon$-chain was purchased from Kallestad Laboratories; ${ }^{*}$ it was processed the same way as the antisera prepared in our laboratory (heat inactivation, immunoadsorption, and absorption on red cells).

All antisera were used undiluted or diluted $(1: 10,1: 20$, $1: 40,1: 80$ ) in saline. They were checked for lymphocytotoxic activity on a panel of leukocytes from various donors in the presence of complement (guinea pig serum) by trypan blue exclusion. No cytotoxic effect was found in any of the sera used. The presence of agglutinating antibodies was also checked on this panel. No such antibodies were found.

${ }^{3}$ Lipo-hepin, Riker Laboratories, Northridge, Calif.

'Kallestad Laboratories, Inc., Minneapolis, Minn.
Sheep red blood cells. SRBC, collected in Alsever's solution, were washed three times in saline and suspended in saline at a final concentration of $4 \times 10^{7}$ cells $/ \mathrm{ml}$.

\section{Experimental Procedures}

The method of rosette formation was based on the technique described by Bach, Dormont, Dardenne, and Balner (1). In each test, $0.05 \mathrm{ml}$ of the lymphocyte suspension was used. In the inhibition studies, lymphocytes were incubated at $37^{\circ} \mathrm{C}$ with $0.05 \mathrm{ml}$ of antiserum (undiluted or diluted in saline) for $1 \mathrm{hr}$ before addition of SRBC. Control specimens were incubated in $\mathrm{PBS}$ for $1 \mathrm{hr}$ at $37^{\circ} \mathrm{C}$. SRBC were added to obtain a final ratio of eight SRBC for every lymphocyte. The mixtures were spun at $200 \mathrm{~g}$ for $5 \mathrm{~min}$ at room temperature. The cells were gently resuspended and 500 lymphocytes were inspected for rosette formation in a hemocytometer at a magnification of $\times 100$. A rosette-forming cell (RFC) was defined as a lymphocyte which had three or more SRBC adherent to its surface; the number of RFC was expressed per 100 lymphocytes. Since the liver and the bone marrow contained other types of cells, specifically, large mononuclear cells, only cells morphologically resembling lymphocytes were counted. If no $\mathrm{RFC}$ were found after viewing 500 lymphocytes, at least 3500 more lymphocytes were evaluated. Only cells with the morphology of lymphocytes were found to form rosettes. The tests performed without antiserum were always run in duplicate and showed a maximum variation of $10 \%$, except in the fetal thymus which had a $5 \%$ variation. The results are given as the mean of two determinations. Sufficient fetal bone marrow cells were not available to run duplicate experiments, and the results are those of one determination for each fetus in these instances.

\section{RESULTS}

\section{Numbers of RFC}

Fetal thymus. At $11 \mathrm{wk}$ of gestation, $15 \%$ of the thymocytes were RFC (Table I). With the exception of fetuses 1 and 5, all embryonic RFC were completely surrounded by SRBC (seven or more SRBC). The RFC of fetuses 1 and 5 were surrounded by only three or four SRBC. The percentage of RFC varied, but was found to be as high as $65 \%$ at $15 \mathrm{wk}$, with gradually

\section{TABLE II}

Rosette-Forming Cells in the Blood of 50 Normal Adults in the Absence and in the Presence of Different Antisera

\begin{tabular}{ccc}
\hline Antiserum & Mean & Range \\
Controls & $\%$ & $\%$ \\
Heavy-chains & 12 & +-40 \\
$\alpha$ & & \\
$\gamma$ & 10 & $0-0$ \\
$\epsilon$ & 0 & $0-35$ \\
$\mu$ & 7 & $0-0$ \\
Light-chains & 0 & $1-40$ \\
$\kappa$ & 8 & $2-39$ \\
$\lambda$ & 8 & \\
\hline
\end{tabular}


fewer RFC found in later weeks. RFC of the oldest fetuses tended to be in clusters.

Fetal blood. Only a small percentage of RFC was found in the fetal blood lymphocytes studied. These RFC were completely surrounded by the SRBC except in fetuses 1 and 5 .

Fetal spleen. The RFC appeared at around 13-14 conceptual wk of age. Since no RFC were found in fetuses 2,3 , and 4 after counting twice 4000 cells, the difference between this group and the oldest fetuses (where $0.5 \%$ of RFC was found after counting twice 500 cells $)$ is statistically significant $(P<0.001$ by Poisson approximation).

Fetal liver. RFC were found in 2 of the 10 specimens studied. The number of RFC was small in both specimens, each of which was derived from 17- to 18wk fetuses.

Fetal bone marrow. For technical reasons, only six bone marrows were examined. The bone marrow of fetus 11 had many red cells, which may suggest some blood contamination. Specimens from the other fetuses were relatively poor in red blood cells and probably represented a pure marrow sample. In these, very few or no RFC were found.

Blood. Normal subjects. The peripheral blood lymphocytes of 50 normal individuals had a mean of $12 \%$ RFC with a range of $4-40 \%$ (Table II). On repeated examinations in any one individual, the percentage of RFC was found to vary approximately $25 \%$ about that person's mean. A slight decrease in the number of RFC was noted after $60 \mathrm{~min}$ of incubation at $37^{\circ} \mathrm{C}$. The results are given after this period of time because, in the studies done with antisera, incubation lasted $1 \mathrm{hr}$;

TABLE III

Rosette-Forming Cells in Various Diseases

\begin{tabular}{|c|c|c|c|}
\hline \multirow[b]{2}{*}{ Diseases } & \multirow{2}{*}{$\begin{array}{l}\text { Without } \\
\text { antiserum }\end{array}$} & \multicolumn{2}{|c|}{ In presence of } \\
\hline & & Anti- $\gamma$ & Anti- $\mu$ \\
\hline & $\%$ & $\%$ & \\
\hline \multicolumn{4}{|c|}{ Acquired hypogamma-globulinemia } \\
\hline A & 12 & 8 & 2 \\
\hline B & 9 & 1 & 2 \\
\hline $\mathrm{C}$ & 5 & 0 & 2 \\
\hline \multicolumn{4}{|c|}{ Wiskott-Aldrich syndrome } \\
\hline A & 1 & N.D.* & N.D. \\
\hline B & 1 & N.D. & N.D. \\
\hline $\mathrm{C}$ & 0.5 & N.D. & N.D. \\
\hline $\mathrm{D}$ & 1 & N.D. & N.D. \\
\hline \multicolumn{4}{|c|}{ Nezelof syndrome } \\
\hline A & 0 & N.D. & N.D. \\
\hline
\end{tabular}

* N.D., not done.
TABLE IV

Inhibition of Rosette Formation with Antisera to Heavy-Chains and Light-Chains in Thymocytes of Human Fetuses

\begin{tabular}{rcrrrrr}
\hline & & \multicolumn{5}{c}{ Inhibition with antiserum to } \\
\cline { 3 - 7 } Fetus & $\begin{array}{c}\text { Gestational } \\
\text { age }\end{array}$ & $\gamma$ & $\mu$ & $\alpha$ & $\kappa$ & $\lambda$ \\
\hline & $w k$ & $\%$ & $\%$ & $\%$ & $\%$ & $\%$ \\
2 & 12 & 94 & 8 & 10 & 86 & 93 \\
3 & 12 & 75 & 0 & 0 & 6 & 2 \\
4 & 13 & 45 & 13 & 0 & 0 & 0 \\
5 & $13-14$ & 96 & 66 & N.D.* & N.D. & N.D. \\
6 & $13-14$ & 98 & 69 & 2 & 0 & 0 \\
8 & 15 & 85 & 65 & 0 & 52 & 5 \\
10 & 17 & 89 & 80 & 0 & 0 & 0 \\
11 & 18 & 66 & 75 & N.D. & N.D. & N.D. \\
12 & 19 & 100 & 100 & 11 & 0 & 42 \\
13 & 19 & 99 & 98 & 6 & 2 & 7 \\
\hline
\end{tabular}

* N.D., not done.

both determinations of RFC were done simultaneously. No relation could be found between the number of $\mathrm{RFC}$ and the ABO group or the titer of serum-agglutinating antibody against SRBC. Subjects with a high percentage of RFC did not show a high hemagglutinating titer.

Blood. Immunological disorders. Three patients with acquired hypogammaglobulinemia showed respectively 12,9 and $5 \%$ of blood RFC. Four patients with Wiskott-Aldrich syndrome showed respectively $1,1,1.5$, and $1 \%$ of blood RFC. One patient with Nezelof syndrome showed a complete absence of RFC in the peripheral blood (Table III).

\section{Effect of the different antisera on rosette formation}

Fetus. Lymphocytes from fetal thymus were studied with undiluted antisera because of the small number of fetal cells available. There was a constant inhibition of rosette formation with antiserum to $\gamma$-chains. (Table IV). The inhibition with antiserum to $\mu$-chain became significant between 13 and 14 wk. Inhibition with anti$\alpha$-chain was interpreted as not meaningful, since it was within the range of the error of the method. Only fetus 2 showed an inhibition with anti-k- and anti- $\lambda$-chain sera, while fetus 8 had a significant decrease of RFC with anti-k-chain serum and fetus 12 with anti- $\lambda$-chain serum. Lymphocytes from the peripheral blood, spleen, and liver of fetuses $5,8,11$, and 13 were studied, and complete inhibition was found with anti- $\gamma$ - or anti- $\mu$ chain sera only. The other antisera had no inhibitory effect. The effect of the antisera was not studied in the fetal bone marrow because of the small number of these cells.

Adults. Rosette formation by cells from normal adults was always completely inhibited by undiluted 
antisera to both $\gamma$ - and $\mu$-chains (Table II). Antiand anti- $\lambda$, as well as anti- $\alpha$ and anti- $\epsilon$, varied in their effects. In the few patients in whom anti- $\epsilon$ produced marked inhibition of rosette formation, no allergic background was found. With diluted antisera, the inhibition of the rosette formation was gradually decreased and with dilutions higher than $1: 40$, inhibition with anti- $\gamma$ and anti- $\mu$ was completely abolished.

Three patients with acquired hypogammaglobulinemia were studied. They responded differently from normal controls in that the inhibition of rosette formation with undiluted antisera to $\gamma$ - and $\mu$-chains was not always complete (Table III).

\section{DISCUSSION}

Rosette-forming cells were found in all thymocyte samples tested. The lowest numbers of fetal thymic RFC (FT-RFC) were found in the youngest fetus (11 wk) and in fetus $5 .^{5}$ At around the 15 th wk, up to $65 \%$ of fetal thymocytes had the ability to bind to SRBC. This gestational period may be significant in view of the observation by Papiernik that maximal PHA stimulation of fetal thymocytes also occurs at this time (9).

Lymphocytes with the ability to bind to SRBC appear to be, at the gestational ages studied, chiefly present in the thymus. However, there were always thymocytes free of SRBC suggesting that this property may be characteristic of only some population(s) of thymic cells. In contrast, the percentage of RFC outside the thymus was low, except in fetus $11,18 \mathrm{wk}$ of age, which showed a marked percentage of RFC outside the thymus associated with the lowest percentage of FT-RFC found around this period.

The apparent decrease of FT-RFC in the elder fetuses may be purely explained on the basis of morphological changes in the thymus, that is, enlargement of the cortical area (9). Migration of the RFC outside the thymus is an alternate explanation for this decrease. This latter hypothesis would be consistent with the slight increase in the blood and spleen RFC of the elder fetuses. However, the number of fetuses studied is too small to draw any definite conclusions in this regard, and other possibilities such as the maturation of receptors for SRBC or the presence of a thymic hormone, should also be considered to explain the appearance of the blood RFC.

Six specimens of bone marrow were studied and, except for fetus 11, the percentage of RFC was always

\footnotetext{
${ }^{5}$ Fetus 5 showed an abnormal pattern when compared to fetuses of the same gestational age: each FT-RFC had only three to four SRBC clinging to it, and its thymocytes had a low response to PHA for this period of gestation. (Stites, D. P., M. C. Carr, and H. H. Fudenberg. Unpublished observation.)
}

very low when compared to the number of FT-RFC. Overall, the absolute numbers of lymphoid-like cells recoverable from the thymus were at least 10 -fold those recoverable from the bone marrow in the age range of the fetuses studied. ${ }^{\text {T }}$ Therefore. if RFC are formed in the bone marrow, their number would probably be extremely small compared to the thymus, although a very high turnover rate could conceivably allow the marrow to be the source. The fetal spleen and liver are thought to be the site of origin of stem cells $(10,11)$. The finding of blood RFC in the youngest fetuses when no RFC were found in the spleen or in the liver of the same fetuses makes it very unlikely that these organs serve as the direct source of the blood RFC at this period of gestation.

These observations suggested to us that the property of spontaneous rosette formation by the blood lymphocytes may be chiefly one of thymic-derived cells.

To support this hypothesis, patients with immunological disorders were studied. The group with humoral deficiency included three patients with acquired hypogammaglobulinemia who showed a percentage of RFC in the normal range. In contrast, patients with impairment or absence of cellular immunity showed a decrease or absence of blood RFC. The four patients with Wiskott-Aldrich syndrome showed a low number of blood RFC and an impairment of their cellular immunity as tested by classical parameters (phytohemagglutinin response, production of migration inhibitory factor, and skin tests). One patient with Nezelof syndrome, a disease characterized by an hypoplasia of the thymus and a complete lack of cellular immunity, had no blood RFC (12). Furthermore, when patients with Wiskott-Aldrich syndrome were treated with transfer factor (T. F.), only the ones who responded to this treatment by the conversion of skin tests, the production of migration inhibitory factor, and by freedom of infections showed an increase (from 1 to 7 or $8 \%$ ) in their blood RFC. In contrast, one patient did not respond to T. F. by clinical and laboratory parameters and did not increase his number of blood RFC.?

These findings suggest that blood RFC are related to the status of cell-mediated immunity which is considered to be a thymus-dependent function. Two indirect arguments in favor of the $\mathrm{RFC}$ being thymus derived should also be mentioned. Namely that rosette inhibition by ALS in vitro correlates very well with ALSinduced delay in skin graft rejection (1) and that, as shown earlier, a strong parallel exists between inhibition of RFC and inhibition of DNA synthesis of $1 \mathrm{ym}-$

\footnotetext{
${ }^{6}$ Carr, M. C., I. P. Stites, and H. H. Fudenberg. Unpublished observations.

${ }^{7}$ Wybran, J., L. E. Spitler, A. S. Levin, and H. H. Fudenberg. In preparation.
} 
phocytes cultured with $\mathrm{PPD}$, in presence of antisera to human immunoglobulins (the response to PPD is mainly a T-cell function) (13).

For all these reasons, it is suggested that the blood RFC is likely to be mainly thymus derived and therefore can be considered as a marker of some population(s) of thymus-derived cells in humans.

In mice the RFC has been extensively studied. It has been shown by numerous authors that some RFC may bear the theta antigen, a marker of thymus-derived cells (14). RFC in nonimmunized mice are involved in antigen recognition and can originate in both thymus and bone marrow (15-21). However, the percentage of $\mathrm{RFC}$ in man is at least 100 -fold that found in the mouse (21) and the phenomenon of human rosette formation perhaps involves mechanisms other than those in the mouse. In the guinea pig, macrophages and homologous or autologous thymocytes adhere together without the participation of any known action of antibodies (22). This property of adhesiveness may be unique to the thymic cell and relevant to the high number of RFC found in the human fetal thymus. Some other nonimmunological mechanisms (e.g. incubation of lymphocytes at $4^{\circ} \mathrm{C}$ increases the number of adult human RFC) may be involved in human rosette formation $(3,4)$.

Another aspect of our findings deals with the inhibition of RFC by antisera to heavy-chains, raising the possibility of the presence of heavy-chain determinants on thymic cells. The validity of these inhibition studies depends upon the specificity of the antisera used and also on the knowledge of the basic mechanisms involved in the human rosette formation. Monospecificity was carefully checked by hemagglutination inhibition. The existence of heteroantibodies is unlikely since these antisera were neither agglutinating nor cytotoxic, in the presence of complement, against a panel of human leukocytes. The finding of increasing inhibition on FTRFC by goat anti- $\mu$ serum argues for the specificity of this antiserum. Indeed, the absence of inhibition with anti- $\alpha$ serum, which was produced in the same species as anti- $\mu$, gives an internal control. Furthermore, if this antiserum was acting nonspecifically, one might not expect the gradual pattern of inhibition seen here, but rather a random, total, or absent inhibition.

The inhibition with anti- $\gamma$ serum introduces the possibility that $\gamma$-chain determinants are present on these cells. However, the inhibition with anti- $\gamma$ serum was always present in FT-RFC which may suggest nonspecific mechanisms. Only in one patient with acquired hypogammaglobulinemia the blood RFC was almost not inhibited with anti- $\gamma$ serum; this may account for the presence of a lesser amount of $\gamma$-chains on these cells which would be expected if these $\gamma$-chains are ab- sorbed on the RFC. However, patients with acquired hypogammaglobinemia may present some impairment of their cellular immunity (23); therefore, their thymus-derived lymphocytes cannot be validly compared with normal lymphocytes and the incomplete inhibition with anti- $\gamma$ serum in hypogammaglobulinemia does not conclusively argue for specificity. For all these reasons, we feel that the inhibition, at least for anti- $\mu$ serum, is most likely to be related to the presence of antibodies to heavy-chains than to nonspecific or nonimmunological mechanisms.

The inhibition of rosette formation by these antisera does not mean that the receptors for SRBC must be immunoglobulins. Indeed, these antisera may act by steric hindrance rather than by a direct masking of receptors for SRBC. The results obtained with the adult blood RFC do not agree with a study done by Coombs, Gurner, Wilson, Holm, and Lindgren (3). These authors could not inhibit the rosette formation with antisera directed against heavy-chains. However, their study differs at least by two points from the present one. They used lymphocytes stored in liquid nitrogen and antisera diluted 10 -fold with no mention of hemagglutinating titer. Therefore, we feel that these two studies are not comparable, especially since the current results indicate that the inhibition of rosette formation was decreased upon the dilution of the antisera. Indeed, no inhibition of rosette formation was noticed when the antisera were diluted more than 40 -fold.

In the fetal thymus, inhibition of rosette formation by antiserum to $\mu$-chain became significant at approximately 13-14 wk and gradually increased to be complete at the 19th wk. This suggests that the $\mu$-chain determinant appears on thymic cells at around the 13th wk. That the origin of the $\mu$-chain may be endogenous is suggested by Gitlin and Biasucci who found that $\operatorname{IgM}$ can be synthesized by fetal thymocytes at 10.5 conceptional wk (24). An exogenous origin of this $\mu$-chain determinant (by absorption) is possible although unlikely from maternal source since IgM is not believed to be able to cross the human placenta. In our studies rosette formation was also inhibited by anti- $\gamma$ serum. This validity of these results has already been discussed. This observation introduces the possibility that $\gamma$-chain determinant is also on the thymus cells. The origin of this $\gamma$-chain determinant may be maternal since IgG of maternal origin is detected in the serum of early stage fetuses (25). However, a fetal origin is not excluded for these $\gamma$-chain determinants. In contrast, no significant inhibition of rosette formation occurred with anti- $\alpha$ serum. This is consistent with the current evidence that $\operatorname{IgA}$ does not cross the placenta and is not synthesized by the human fetus at this stage. The effect of the antisera to light-chains was variable, per- 
haps because of the relatively weak titer of these antisera or because buried determinants of light-chains exist on the lymphocyte surface.

Using various methods, most investigators (26-32) have found heavy-chains on B-cells which are presumably bone marrow-derived in mammals and involved in humoral immunity (23). On the other hand, few or no heavy-chains were detected on thymocytes. Yet recent studies suggest the possibility that mouse and human thymocytes and T-cells may possess $\mu$-chain or $\mu$-chain-like determinants on their surfaces (33-36). ${ }^{8}$ One of these studies reports the isolation of $\mu$-chains with a molecular weight of 200,000 from human and mouse thymuses (36). In none of these studies was $\gamma$-chains detected.

In conclusion, the study of rosette formation in the lymphoid tissues of 11 - to 19 -wk human fetuses suggested that spontaneous RFC may be chiefly thymus derived. Clinical arguments coming from the study of patients with immunodeficiencies support this hypothesis. The presence of $\mu$-chain on thymic cells is suggested by the inhibition of rosette formation by anti- $\mu$ serum. The possibility of $\gamma$-chain on these cells has been raised. Finally, it is proposed that human blood RFC may be considered as a marker of a substantial population of thymus-derived cells and that the study of these $\mathrm{RFC}$ is a valid tool in assessing patients with immunological disorders.

\section{ACKNOWLEDGMENTS}

This work was supported in part by grants from the U. S. Public Health Service (HD-03939 and HD-05894), the American Cancer Society (ET-13E), and the Jane Coffin Childs Memorial Fund for Medical Research. We thank Dr. Sandy E. Avner (National Jewish Hospital, Denver, Colo.) for letting us study his patient with Nezelof syndrome.

\section{REFERENCES}

1. Bach, J. F., J. Dormont, M. Dardenne, and H. Balner. 1969. In vitro rosette inhibition by antihuman antilymphocyte serum. Correlation with skin graft prolongation in subhuman primates. Transplantation. 8: 265.

2. Brain, P., J. Gordon, and W. A. Willetts. 1970. Rosette formation by peripheral lymphocytes. Clin. Exp. Immunol. 6: 681 .

3. Coombs, R. R. A., B. W. Gurner, A. B. Wilson, G. Holm, and B. Lindgren. 1970. Rosette-formation between human lymphocytes and sheep red cells not involving immunoglobulin receptors. Int. Arch. Allergy Appl. Immunol. 39 : 658.

4. Lay, W. H., N. F. Mendes, C. Bianco, and V. Nussenzweig. 1971. Binding of sheep red blood cells to a large population of human lymphocytes. Nature (Lond.). 230: 531 .

${ }^{8}$ Hammerling, U. Topographical aspects of lymphocyte membranes. Presented at the First International Congress of Immunology, Washington, D. C. 1-6 August 1971.
5. Hertig, A. T. 1968. Human Trophoblast. Charles C Thomas, Publisher, Springfield, Ill. 137.

6. Harris, R., and E. O. Ukaejiofo. 1969. Rapid preparation of lymphocytes for tissue-typing. Lancet. 2: 327.

7. Avrameas, S., and T. Ternynck. 1969. The cross-linking of proteins with glutaraldehyde and its use for the preparation of immunoadsorbents. Immunochemistry. 6: 53.

8. Gold, E. R., and H. H. Fudenberg. 1967. Chromic chloride: a coupling reagent for passive hemagglutination reactions. J. Immunol. 99: 859.

9. Papiernik, M. 1970. Correlation of lymphocyte transformation and morphology in the human fetal thymus. Blood J. Hematol. 36: 470.

10. Tyan, M. L., and L. J. Cole. 1963. Mouse fetal liver and thymus: potential sources of immunologically active cells. Transplantation. $1: 347$.

11. Taylor, R. B. 1965. Pluripotential stem cells in moust embryo liver. Br. J. Exp. Pathol. 46: 376.

12. Nezelof, C., M. L. Jannet, P. Lortholary, B. Labrune, and M. Lamy. 1964. L'hypoplasie héréditaire du thymus: sa place et sa responsabilité dans une observation d'aplasie lymphocytaire normoplasmocytaire et normoglobulinémique du nourrisson. Arch. Fr. Pédiatr. 21: 897.

13. Wybran, J., and H. H. Fudenberg. 1971. Rosette formation, a test for cellular immunity. Trans. Assoc. Am. Physicians Phila. $84: 239$.

14. Raff, M. C. 1969. Theta isoantigen as a marker of thymus-derived lymphocytes in mice. Nature (Lond.). $224: 378$.

15. Greaves, M. F., and E. Möller. 1970. Studies on antigenbinding cells. I. The origin of reactive cells. Cell. Immunol. $1: 372$.

16. Schlesinger, M. 1970. Anti- $\theta$ antibodies for detecting thymus-dependent lymphocytes in the immune response of mice to SRBC. Nature (Lond.). 226: 1254.

17. Bach, J.-F., M. Dardenne, and J.-Y. Muller. 1970. Reconnaissance de l'antigène, in vic'o, par les cellules formant les rosettes spontanées. C. R. Hebd. Séances Acad. Sci. Sér. I) Sci. Nat. (Paris). 270: 2142.

18. Bach. J.-F., J.-Y. Muller, and M. Dardenne. 1970. In riz'o specific antigen recognition by rosette forming cells. Nature (Lond.). 227: 1251.

19. Bach, J.-F., M. Dardenne, and A. J. S. Davies. 1971. Early effect of adult thymectomy. Nat. Neri Biol. 231: 110.

20. Bach, J.-F., and M. Dardenne. 1969. Signification du phénomène de rosette chez la souris non immunisée. C. R. Hebd. Séances Acad. Sci. Sér. D Sci. Nat. (Paris). 269: 751.

21. Bach, J.-F., and M. Dardenne. 1972. Antigen recognition by $\mathrm{T}$ lymphocytes. I. Thymus and marrow dependence of spontaneous rosette forming cells in the mouse. Cell. Immunol. 3 : 1.

22. Siegel, I. 1970. Natural and antibody-induced adherence of guinea pig phagocytic cells to autologous and heterologous thymocytes. J. Immunol. $105: 879$.

23. Fudenberg, H., R. A. Good, H. C. Goodman, W. Hitzig, H. G. Kunkel, I. M. Roitt, F. S. Rosen, D. S. Rowe, M. Seligmann, and J. R. Soothill. 1971. Primary immunodeficiencies: report of a World Health Organization committee. Pcdiatrics. $47: 927$.

24. Gitlin, D., and A. Biasucci. 1969. Development of $\gamma^{r_{1}}$, $\gamma^{\mathbf{A}}, \quad \gamma^{\mathbf{M}}, \beta_{1 \mathrm{C}} / \beta_{1 \mathrm{~A}}, \mathrm{C}^{\prime} 1$ esterase inhibitor, ceruloplasmin, transferrin, hemopexin, haptoglobin, fibrinogen, plas- 
minogen, $\alpha_{1}$-antitrypsin, orosomucoid, $\beta$-lipoprotein, $\alpha_{2}-$ macroglobulin, and prealbumin in the human conceptus. J. Clin. Invest. $48: 1433$.

25. Scheidegger, J. J., E. Martin, and G. Riotton. 1965. L'apparition des diverses composantes antigéniques du sérum au cours du développement foetal. Schweiz. Med. Wochenschr. $86: 224$.

26. Coombs, R. R. A., B. W. Gurner, I. McConnell, and A. Munro. 1970. Immunoglobulin determinants on mouse lymphocytes from blood, lymph nodes, bone marrow, and thymus. Int. Arch. Allergy Appl. Immunol. 39: 280.

27. Pernis, B., L. Forni, and L. Amante. 1970. Immunoglobulin spots on the surface of rabbit lymphocytes. J. Exp. Med. 132: 1001.

28. Rabellino, E., S. Colon, H. M. Grey, and E. R. Unanue. 1971. Immunoglobulins on the surface of lymphocytes. I. Distribution and quantitation. J. Exp. Med. 133: 156.

29. Unanue, E. R., H. M. Grey, E. Rabellino, P. Campbell, and J. Schmidtke. 1971. Immunoglobulins on the surface of lymphocytes. II. The bone marrow as the main source of lymphocytes with detectable surface-bound immunoglobulin. J. Exp. Med. 133: 1188.

30. Rabellino, E., and H. M. Grey. 1971. Immunoglobulins on the surface of lymphocytes. III. Bursal origin of. surface immunoglobulins on chicken lymphocytes. $J$. Immunol. 106: 1418.

31. Jones, G., G. Torrigiani, and I. M. Roitt. 1971. Immunoglobulin determinants on mouse lymphocytes. $J$. Immunol. 106: 1425.

32. Pernis, B., L. Forni, and L. Amante. 1971. Immunoglobulins as cell receptors. Ann. N.Y.Acad. Sci. In press.

33. Greaves, M. 1970. Biological effects of anti-immunoglobulins: evidence for immunoglobulin receptors on $\mathrm{T}$ and B lymphocytes. Transplant. Rev. 5: 45.

34. Klein, E., T. Eskeland, M. Inoue, R. Strom, and B. Johansson. 1970. Surface immunoglobulin moieties on lymphoid cells. Exp. Cell Res. 62: 133.

35. Nossal, G. J. V., N. L. Warner, H. Lewis, and J. Sprent. 1972. Quantitative features of a sandwich radioimmuno-labeling technique for lymphocyte surface receptors. J. Exp. Med. 135: 405.

36. Marchalonis, J. L., J. L. Atwell, and R. E. Cone. 1972. Isolation of surface immunoglobulin from lymphocytes from human and murine thymus. Nat. Neze Biol. 235: 240. 